\title{
RASPBERRY PI BASED POLLUTION AND CLIMATE MONITORING SYSTEM USING INTERNET OF THINGS
}

\author{
Dr. Dhiraj Sunehra \\ Department of Electronics \& Communication Engineering \\ Faculty of Engineering \& Technology \\ Jawaharlal Nehru Technological University Hyderabad, India
}

\begin{abstract}
ABTRACT
In recent years pollution and global warming have increased rapidly. Air and sound pollution is more in urban areas as compared to rural areas due to denser vehicular traffic and rapid industrialization. Air pollution causes long term health effects like lung cancer and heart diseases, and also it causes short term health issues such as headaches, eye infections and throat infection. Air pollution increases the temperature of the Earth's atmosphere which results in global warming. Hence it is necessary to monitor the various climate and pollution parameters such as temperature, humidity, atmospheric pressure, sound, toxic content of hazardous gases, and light intensity. As we need to know the location of the data, we also normally measure the latitude and longitude of the place. In this paper, a pollution and climate monitoring system is developed which can measure the above parameters at regular intervals using appropriate sensors and uploads them on to the webpage using Internet of Things (IoT) technology. The webpage is developed using HTML and PHP. Raspberry Pi3 computer is the central component used for data collection from the sensors and uploading parameters on to the webpage. Python language is used development of the software code. The uploaded pollution and climate parameters of a particular place can be viewed by logging on to the webpage from anywhere in the world.
\end{abstract}

Keywords: Pollution monitoring, Climate monitoring, Global warming, Raspberry Pi3, Python language.

Cite this Article: Dr. Dhiraj Sunehra, Raspberry Pi Based Pollution and Climate Monitoring System using Internet of Things, International Journal of Advanced Research in Engineering and Technology, 10(2), 2019, pp.44-54.

http://iaeme.com/Home/issue/IJARET?Volume=10\&Issue $=2$

\section{INTRODUCTION}

In recent years pollution in urban cities of India has increased drastically. Pollution in cities is more when compared to villages because of emission of dangerous gases from large number of motor vehicles. Emission of hazardous gases from the industrial sector and burning of forests are the main causes of air pollution. Industrial pollution takes on many faces like releases 
unwanted toxins into the air, it contaminates drinking water and also reduces the quality of soil all over the world.

According to the World Health Organization (WHO), Delhi is one among the most polluted cities across the world amongst database of more than 4300 cities, based on the amount of particular matter under 2.5 micrograms found in every cubic meter in air. Air pollution increases the temperature of the Earth's atmosphere which results in global warming. Global warming increases the water level in sea due to thermal expansion, melting of glaciers and ice sheets. Atmospheric changes are a raising concern across the globe. These changes include global warming, air pollution, pressure and humidity changes. It is necessary to keep an eye on the equilibrium of the atmosphere.

The proposed pollution and climate monitoring system monitors the above parameters at regular intervals and provides dynamic data sheet on the webpage which can be accessed from any part of the world. This data sheet can be considered as a reference by the government and other organizations that bother to reduce atmospheric changes.

\section{LITERATURE REVIEW}

Somansh Kumar and Ashish Jasuja presented a real-time air quality management system implemented using Raspberry Pi [1]. This system is tested in Delhi and the measured data is compared with the data provided by the local environment authority. Harsh N. Shah et al implemented an air pollution monitoring system using Arduino Uno that detects the presence of harmful gases and will give an alarm when the air quality goes low [2]. The system displays the air quality in PPM on an LCD and webpage. Sen Gupta and Vu Minh Quan have used wireless sensor networks architecture for implementing a climate monitoring system of greenhouse environment [3]. Nadjet and Mounira have proposed an artificial neural networks model to predict air pollutants concentration in industrial sites [4]. Mitesh Rathod et al implemented a simple system that tracks the pollution levels from a vehicle using MQ-7 gas sensor and location of the vehicle obtained from the Global Positioning System (GPS) is sent to the road transport authority (RTA) [5].

\section{SYSTEM DESCRIPTION}

\subsection{Block Diagram}

Figure 1 shows the block diagram of the climate and pollution monitoring system. In this system, various sensors used for climate monitoring include temperature, humidity and pressure. Sound and gas sensors are used for pollution monitoring. In addition to these sensors, light intensity is also measured. The outputs from the above sensors are fed as inputs to the Raspberry Pi3 board. Pi processes the sensor data at regular intervals and upload onto the webpage along location information obtained from GPS. The output data from Raspberry Pi is not only displayed on the webpage but it is also displayed on LCD screen. 


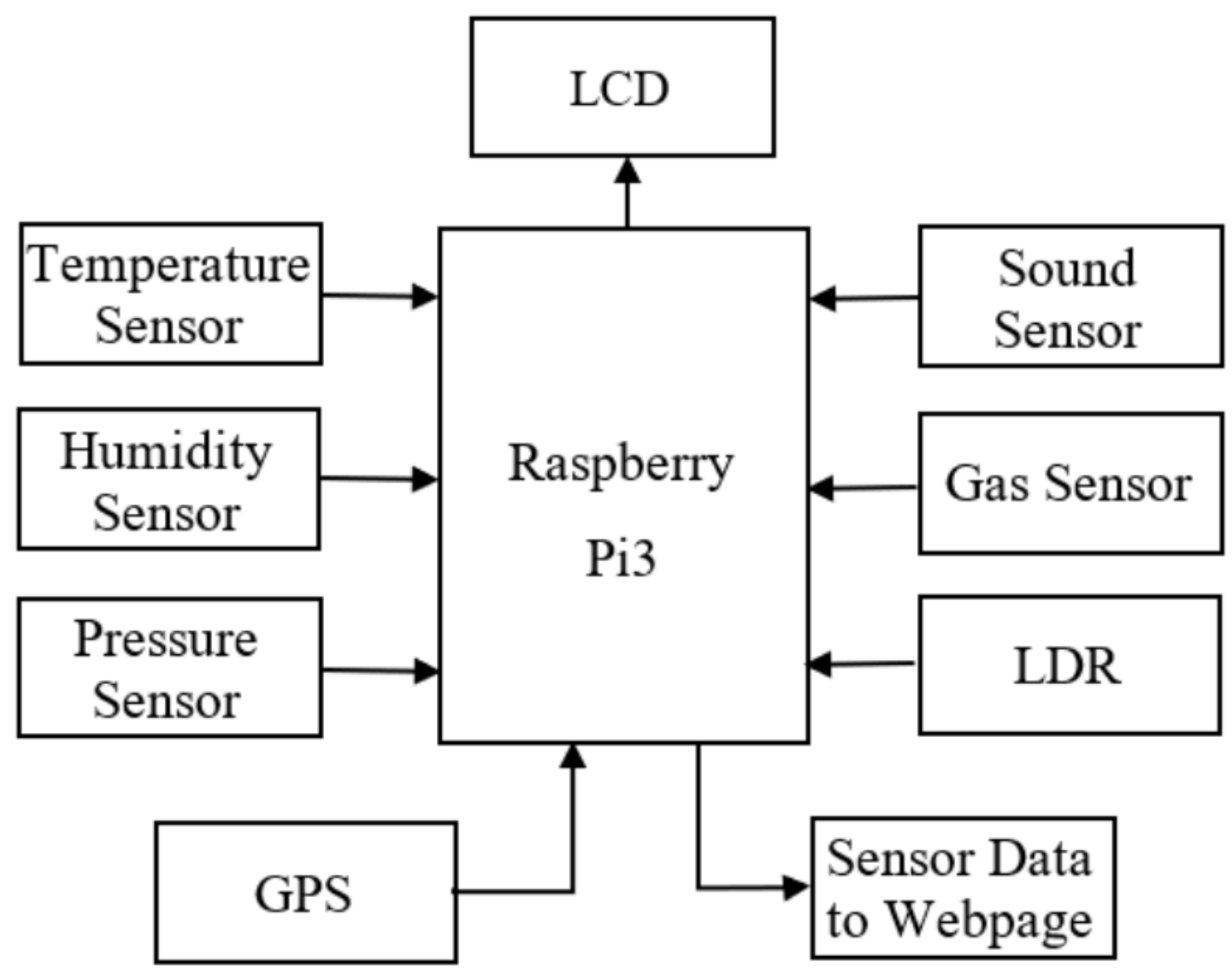

Figure 1 Block Diagram of Pollution and Climate Monitoring System using Raspberry Pi

\subsection{Salient Features of Raspberry Pi3 Board}

Raspberry $\mathrm{Pi}$ is a pocket size minicomputer. Raspberry Pi acts like computer when plugged with monitor. It is having a $1.2 \mathrm{GHz}$, quad-core 64-bit ARM Cortex A53 processor, Video Core IV GPU, a built-in Wi-Fi module, a Bluetooth module, 1 GB SDRAM memory out of which $512 \mathrm{MB}$ is shared with GPU, $3.5 \mathrm{~mm}$ audio jack, one SD card slot that can supports up to 32 GB, 4 USB ports, and one Ethernet port [6].

Raspberry Pi3 consists of total 40 pins out of which 26 pins are GPIO pins, four Vec pins (two pins are $3.3 \mathrm{~V}$ and two pins are $5 \mathrm{~V}$ ), 8 ground pins, 1 TXD pin, 1 RXD pin, 1 SCL pin and 1 SDA pin. Raspberry Pi has one HDMI port and one CSI port. Digital cameras are connected to Raspberry Pi through CSI connector (Figure 2).

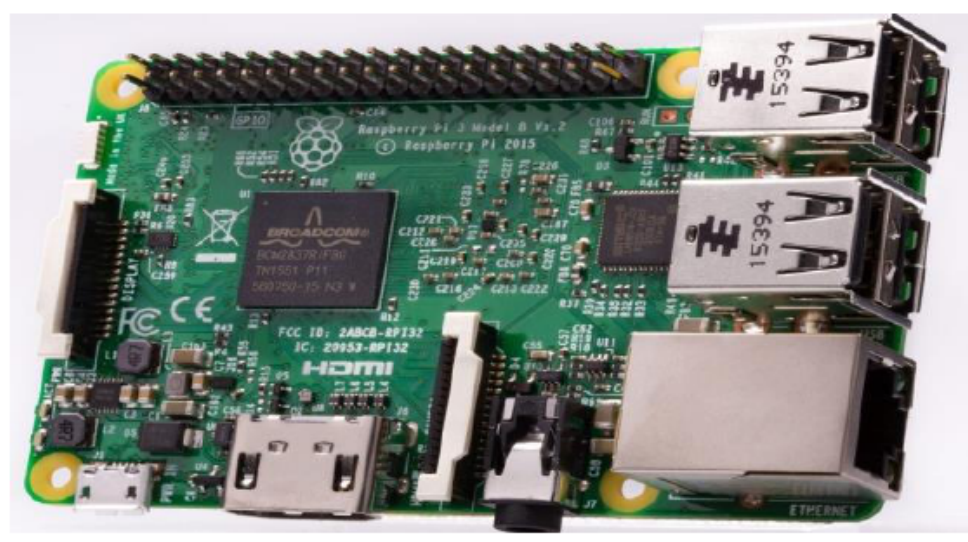

Figure 2 Raspberry Pi3 Model B Board 


\subsection{Temperature and Humidity Sensor}

DHT11 sensor is used to measure temperature and pressure. In DHT11 sensor, there are two components internally:

1. Negative Temperature Coefficient (NTC) Temperature sensing component (Thermistor).

2. Humidity Sensing components.

In NTC component, the resistance of the device decreases when temperature of the environment increases. Temperature sensing components are made with semi conductive materials like ceramic or polymer material. Range of the supply voltage for DHT11 is: +3.5 to $+5 \mathrm{~V}$. It can measure the temperature ranging from: $0-50^{\circ} \mathrm{C}$ with an error of $\pm 2{ }^{\circ} \mathrm{C}$ [7].

In humidity sensing component, there are two electrodes. A moisture holding material is placed in between two electrodes (Figure 3). When there is a change in the environment moisture, the conductivity of the material is changed, hence the resistance between two electrodes is changed according with moisture in environment. Humidity ranging from: $20 \%$ to $90 \%$.

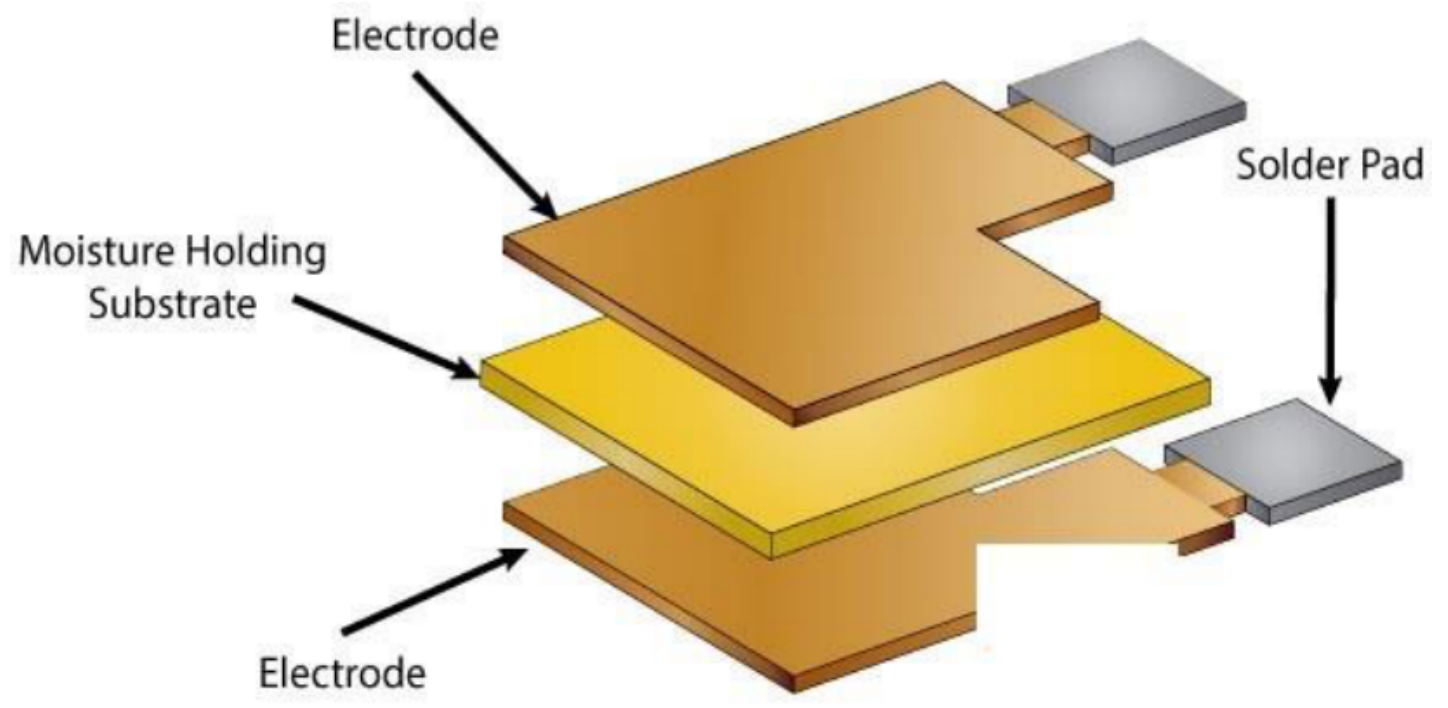

Figure 3 Humidity sensing component

\subsection{Sound Sensor}

Sound sensor has three pins, viz. Vcc, ground, control output pin (Figure 4). Sound sensor is used to find sound pollution in environment. Sound sensor has a microphone which can detect noise/sound in the air, and this data is fed to Raspberry Pi through control output pin. The sensitivity of the sound sensor microphone is $52-48 \mathrm{~dB}$. The frequency range of the sensor is $16-20 \mathrm{KHz}$ and its signal to noise ratio is $54 \mathrm{~dB}$. Sound sensor gives only digital logic output low or high. If it gives logic 0 sound pollution is present, otherwise sound pollution is absent (within limits). 


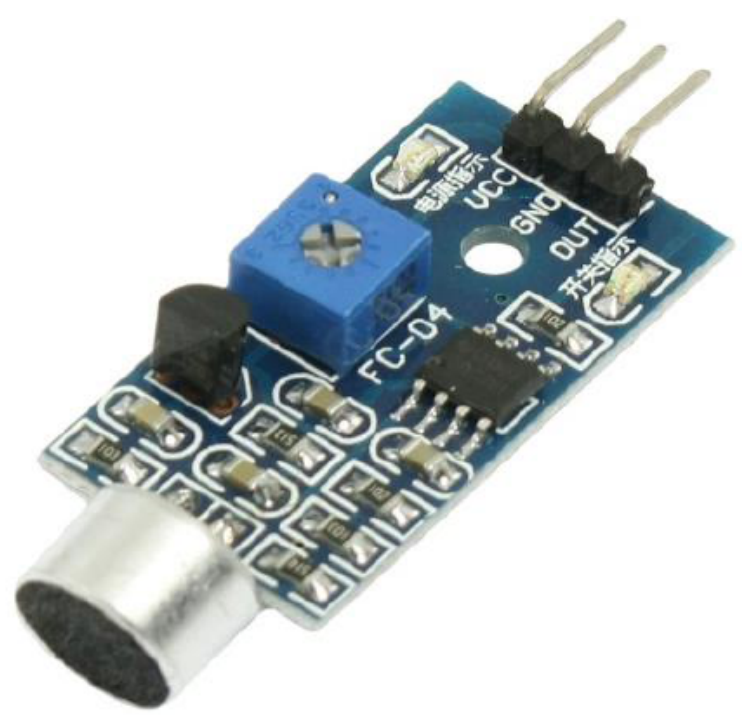

Figure 4 Sound Sensor

\subsection{Gas Sensor}

Gas sensor is used to detect toxic gases and flammable gases present in the environment (Figure 5). MQ-2 gas sensor is highly sensitive to carbon monoxide, methane gas, hydrogen gas, and smoke content present in the air [8]. Power pin is connected to supply voltage (3.3 to 5V). Gas sensor is having a single output pin which is connected to any GPIO pin of the Pi. The ground pin of the gas sensor is connected to any ground pin of Raspberry Pi.

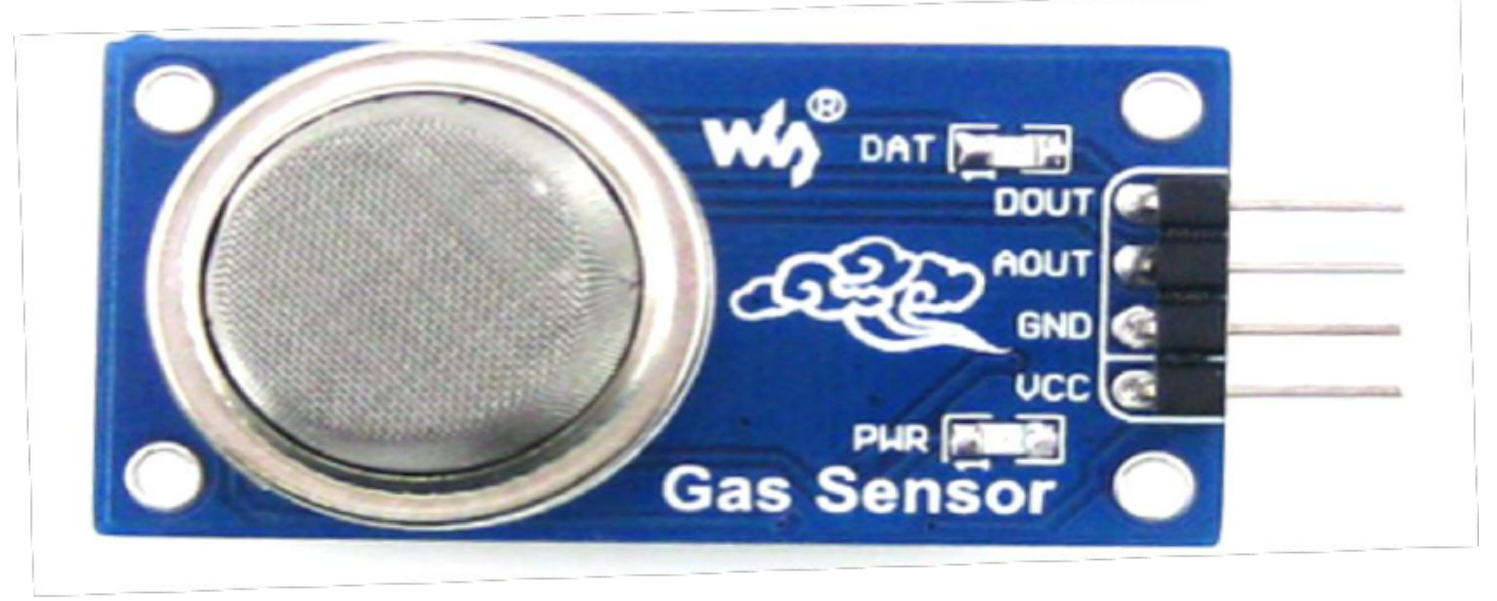

Figure 5 Smoke Sensor

\subsection{Pressure Sensor}

BMP180 pressure sensor is used to find atmospheric pressure, where BMP stands for barometric pressure. Pressure sensor has a total of four pins, viz. $\mathrm{V}_{\mathrm{in}}$, ground, SDA, and SCL pin (Figure 6). BMP180 pressure sensor measures absolute atmospheric pressure. A piezoresistive sensor is present inside the BMP180 pressure sensor. $\mathrm{V}_{\text {in }}$ pin of pressure sensor requires a supply voltage of $3.3 \mathrm{~V}$. Inside the pressure sensor, E2PROM, I2C interface are present. The maximum speed of $\mathrm{I} 2 \mathrm{C}$ interface is $3.5 \mathrm{MHz}$. This sensor can measure the pressure in the range of $300 \mathrm{mbar}$ to $1100 \mathrm{mbar}$. Serial data pin of the pressure sensor is connected to SDA pin of Raspberry Pi, and SCL pin of the pressure sensor is connected to the clock pin of Raspberry Pi. 


\section{Front view}

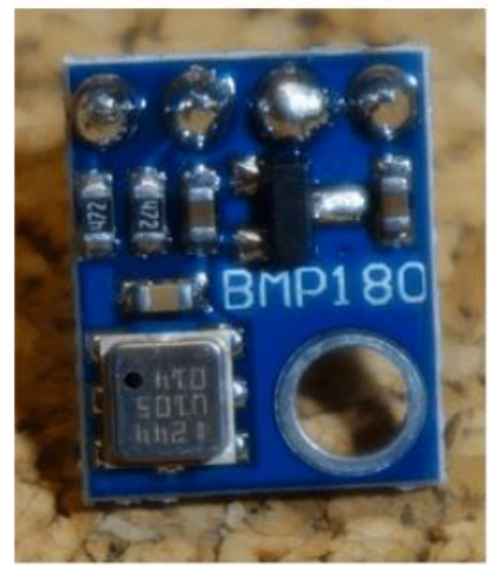

Back view

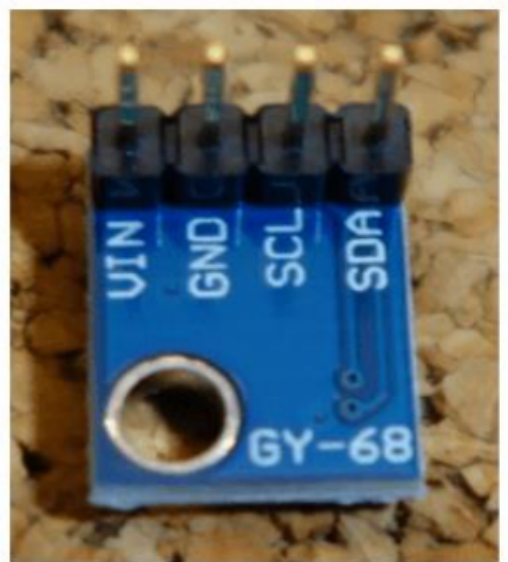

Figure 6 BMP180 Pressure Sensor

\subsection{LDR Sensor}

Light Dependent Resistor (LDR) sensor can measure the intensity of sunlight for identification of day and night. LDR internally has a resistance whose internal resistance varies inversely with light intensity. If the light intensity increases, LDR resistance decreases and vice versa.

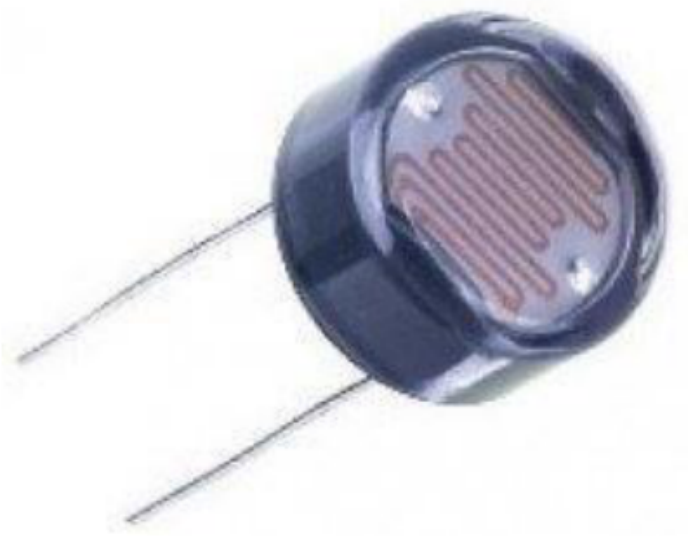

Figure 7 LDR Sensor

\subsection{LCD}

Liquid Crystal Display (LCD) is an electronic display device. A $16 \times 2$ display has two lines, each line has 16 characters (Figure 8). LCD has two internal registers, viz. command register which stores instructions given to the LCD, data register which stores the ASCII value of character to be displayed on LCD.

\subsection{Global Positioning System}

Global Positioning System (GPS) is developed by the U.S. Department of Defense in the year 1973. It is a satellite based navigation system which can provide user location in three dimensions, and time information. GPS has three segments, viz. Space segment, Control segment and User segment.

Space segment consists of atleast 24 satellites placed in six orbital planes, each inclined at angle of $55^{\circ}$ to the equatorial plane. These satellites revolve around the earth at a height of 20,200 $\mathrm{km}$ approximately. The space segment transmits the navigation signals on two L-band 
frequencies. The control segment consists of a global network of monitor stations and a master control station at Colorado Springs, USA [9]. It computes precise locations of the satellites, monitors satellite broadcasts and system integrity to ensure constellation health and accuracy. The user segment consists of GPS receivers which receive satellite signals and compute the user location in terms of latitude and longitude.

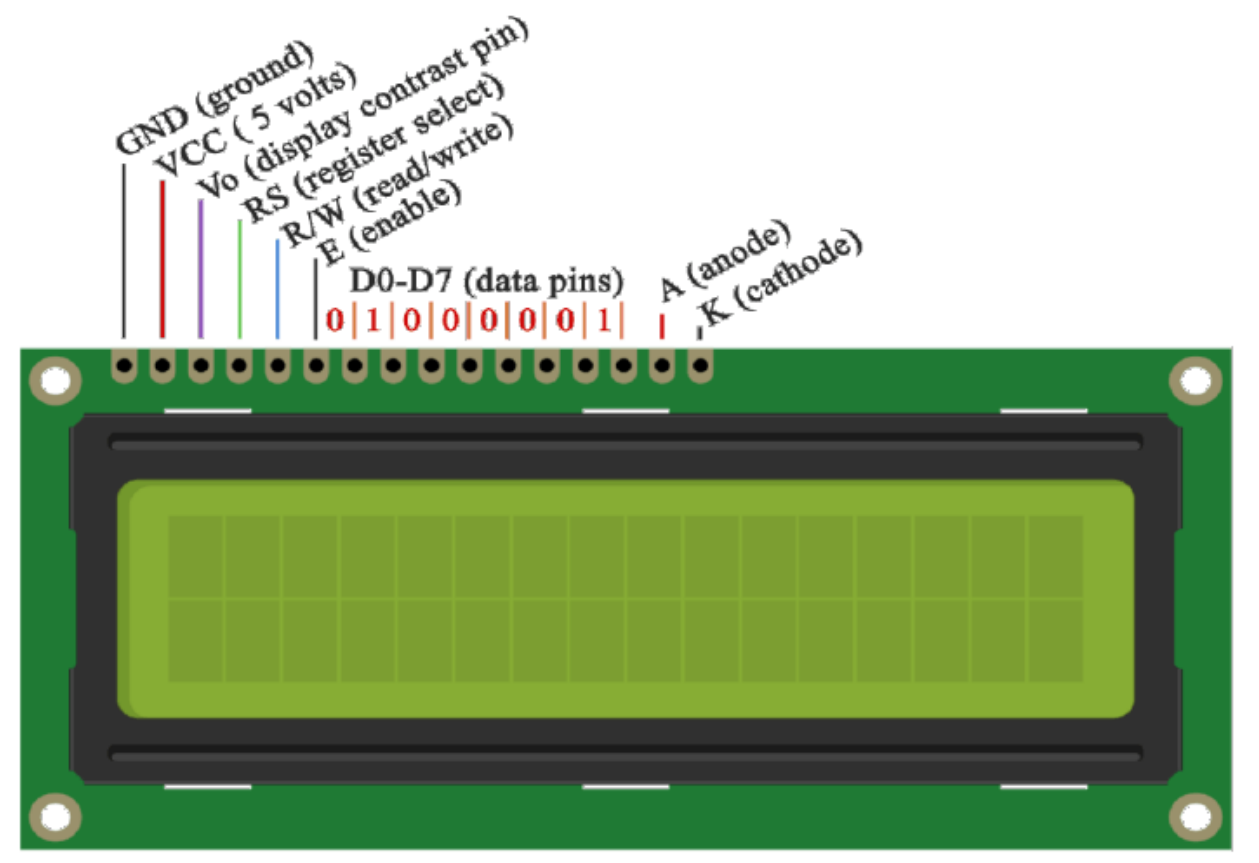

Figure 8 LCD Display

To implement the pollution and climate monitoring system, various software tools including Python, ExtraPuTTY, HTML and PHP are used [10,11,12].

\section{SCHEMATIC DIAGRAM AND FLOWCHART}

Figure 9 shows the schematic diagram of the pollution and climate monitoring system.

Figure 10 shows the flowchart of the sequence of events that occur in the pollution and climate monitoring system. The Raspberry $\mathrm{Pi}$ is initialized. First, the analog values from the temperature, humidity and pressure sensors are fed to the $\mathrm{Pi}$, and then uploaded onto the webpage. Then the digital values from the sound, gas and LDR sensors are checked with threshold values. If any value is more than threshold value, display output as 0 corresponding to that sensor, otherwise display output as 1 .

\section{EXPERIMENTAL SETUP AND RESULTS}

Figure 11 shows the experimental setup of Raspberry Pi based pollution and climate monitoring system using IoT. The various sensors including temperature sensor, humidity sensor, sound sensor, gas sensor, pressure sensor, and LDR are interfaced to the Raspberry Pi along with the LCD and GPS module.

All the sensed data from various sensors and GPS location are uploaded onto the webpage continuously. In the webpage along with relevant data, date and time stamp are also provided. By using this feature, user can easily understand the environment condition at a particular time. Figure 12 shows the Webpage view of the results of Raspberry Pi based pollution and climate monitoring system using IoT. 
Raspberry Pi Based Pollution and Climate Monitoring System using Internet of Things

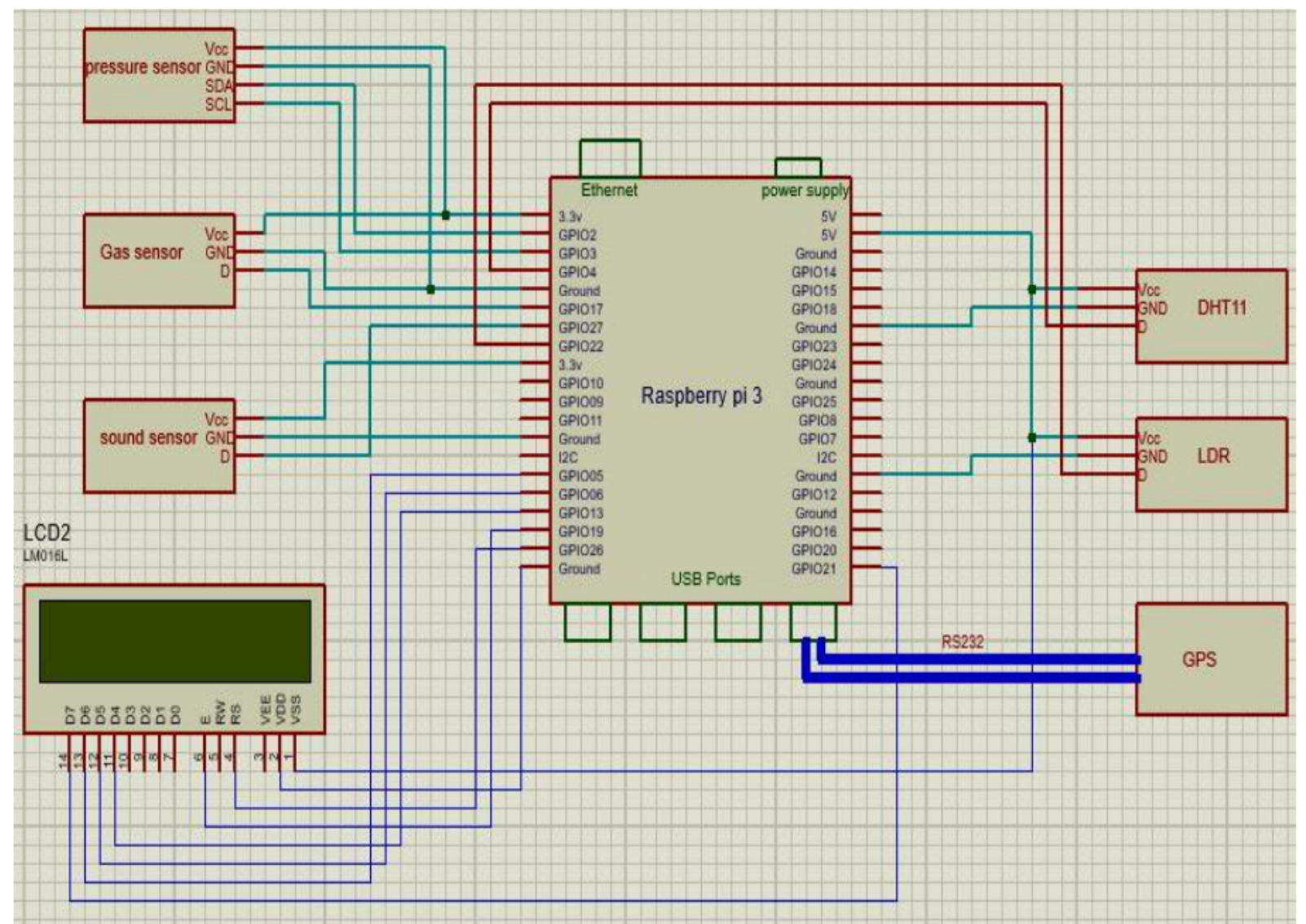

Figure 9 Schematic Diagram of the system

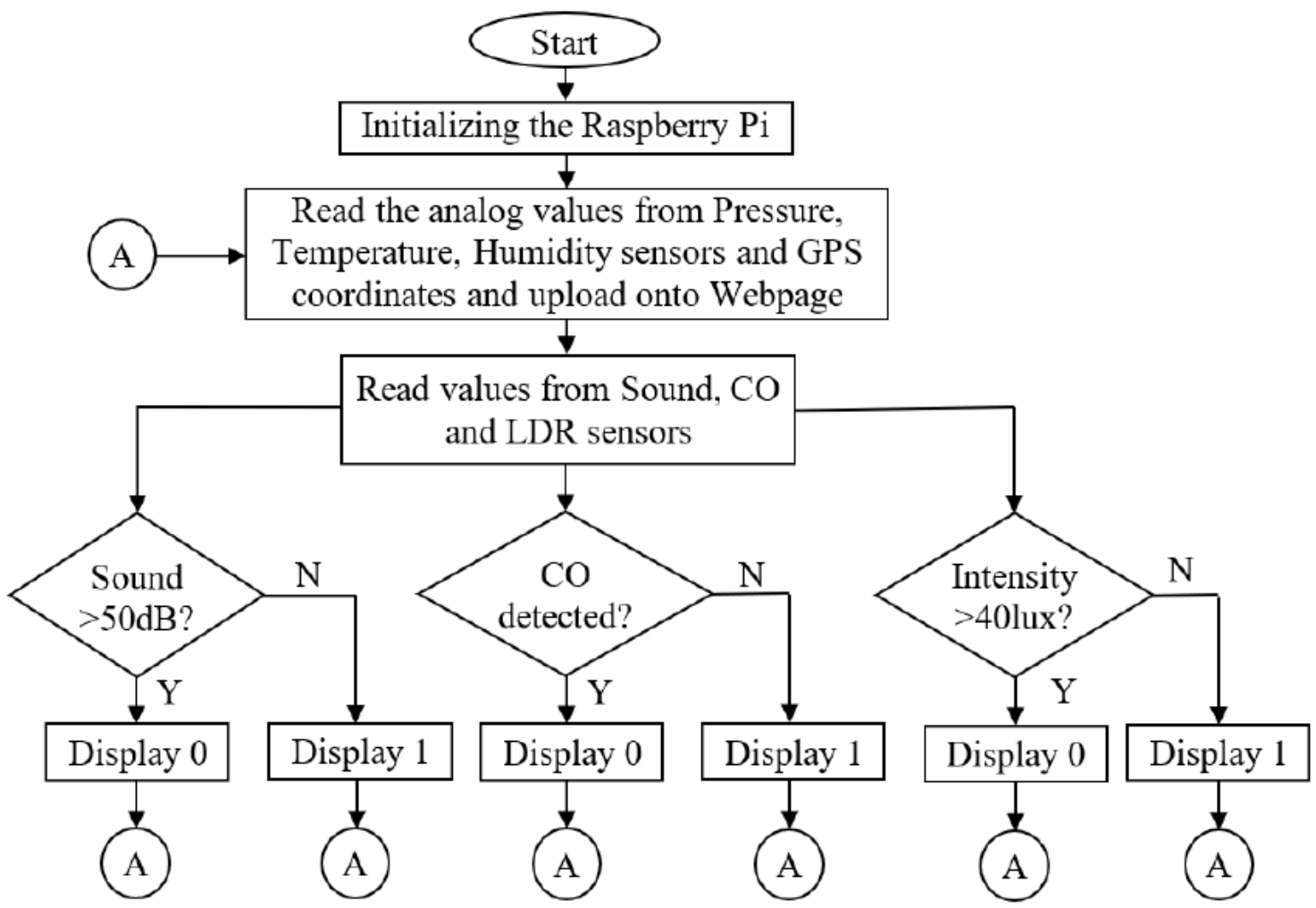

Figure 10 Flowchart of the sequence of events that occur 


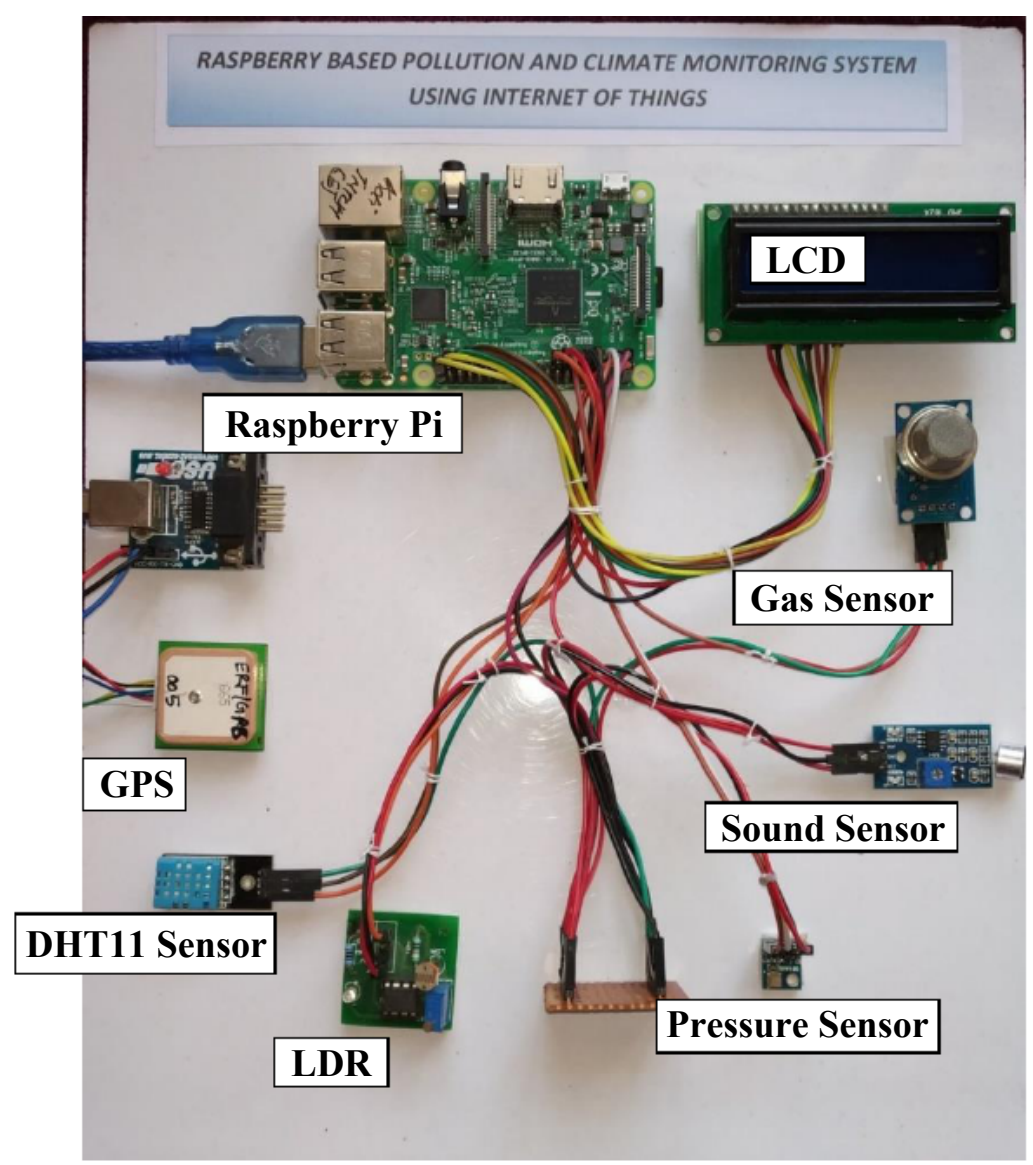

Figure 11 Experimental Setup of Pollution \& Climate Monitoring System using Raspberry Pi

$\leftarrow \rightarrow$ C (1) Not secure| 192.168 .11 / $/$ main/mainphp

\section{Raspberry Pi Based Pollution and Climate Monitoring using IoT}

\begin{tabular}{|c|c|c|c|c|c|c|c|c|c|c|}
\hline SI_No & Date & Time & Gas & Sound & LDR & Temp & Humidity & Pressure & Lattitude & Longitude \\
\hline 1 & $09 / 26 / 18$ & 03:53:04 PM & 1 & 0 & 1 & $30.2 \mathrm{C}$ & $75.0 \%$ & $953.82 \mathrm{mbar}$ & 17.3676095 & 78.527595 \\
\hline 2 & $09 / 26 / 18$ & 03:54:46 PM & 1 & 0 & 1 & $30.1 C$ & $75.0 \%$ & $953.89 \mathrm{mbar}$ & 17.3675356667 & 78.52759 \\
\hline 3 & $09 / 26 / 18$ & 03:55:34 PM & 1 & 0 & 1 & $30.1 \mathrm{C}$ & $74.0 \%$ & $953.95 \mathrm{mbar}$ & 17.367535 & 78.5275916667 \\
\hline 4 & $09 / 26 / 18$ & 03:56:26 PM & 1 & 0 & 1 & $30.2 \mathrm{C}$ & $71.0 \%$ & $953.86 \mathrm{mbar}$ & 17.3675341667 & 78.5275916667 \\
\hline 5 & $09 / 26 / 18$ & 03:57:16 PM & 1 & 1 & 1 & $30.3 \mathrm{C}$ & $74.0 \%$ & $953.89 \mathrm{mbar}$ & 17.3675335 & 78.52759 \\
\hline 6 & $09 / 26 / 18$ & 03:58:06 PM & 1 & 1 & 1 & $30.2 \mathrm{C}$ & $75.0 \%$ & $953.77 \mathrm{mbar}$ & 17.367533 & 78.52759 \\
\hline 7 & $09 / 26 / 18$ & 03:58:58 PM & 1 & 1 & 1 & $30.3 \mathrm{C}$ & $73.0 \%$ & $953.87 \mathrm{mbar}$ & 17.3675305 & 78.5275883333 \\
\hline 8 & $09 / 26 / 18$ & 03:59:53 PM & 1 & 1 & 1 & $30.3 \mathrm{C}$ & $74.0 \%$ & $953.78 \mathrm{mbar}$ & 17.367529 & 78.5275883333 \\
\hline 9 & $09 / 26 / 18$ & 04:00:46 PM & 1 & 1 & 1 & $30.4 \mathrm{C}$ & $73.0 \%$ & $953.79 \mathrm{mbar}$ & 17.3675286667 & 78.52759 \\
\hline 10 & $09 / 26 / 18$ & 04:01:36 PM & 1 & 0 & 1 & $30.3 \mathrm{C}$ & $73.0 \%$ & $953.73 \mathrm{mbar}$ & 17.3675278333 & 78.5275883333 \\
\hline 11 & $09 / 26 / 18$ & 04:02:46 PM & 1 & 0 & 0 & $30.3 \mathrm{C}$ & $71.0 \%$ & $953.75 \mathrm{mbar}$ & 17.3675268333 & 78.5275883333 \\
\hline
\end{tabular}

Figure 12 Experimental Results of Pollution \& Climate Monitoring System on Webpage 
The results can also be viewed on the LCD as shown in the following snapshots:

\section{GPS module output on LCD}

GPS module computes the latitude and longitude values and gives the corresponding values to Raspberry Pi, which are displayed on LCD display (Figure 13). These coordinates correspond to Hyderabad.

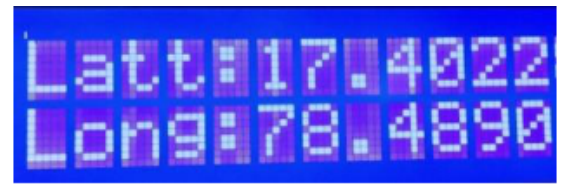

Figure 13 Output values of latitude and longitude on LCD

\section{DHT 11 sensor output on LCD}

Figure 14 shows the sample temperature and humidity values of atmosphere. Here temperature is measured in degrees and humidity is measured in percentage.

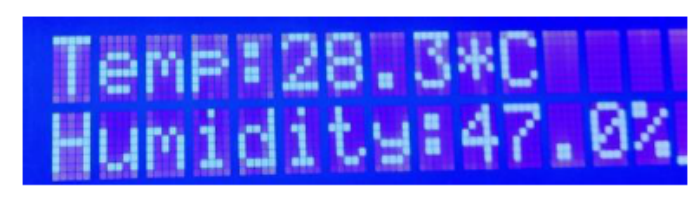

Figure 14 Output values of temperature and humidity on LCD

\section{LDR and Pressure sensor output on LCD}

\section{Case 1}

Figure 15 shows the Pressure value on the LCD screen, measured in mbar and LDR output is shown as 1 . This means that light is absent.

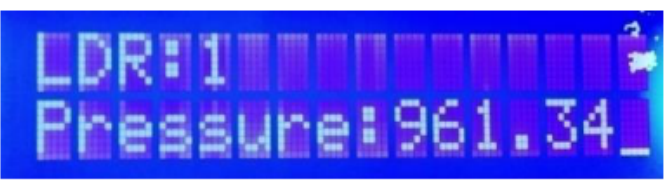

Figure 15 Output values of LDR and pressure on LCD for Case 1

\section{Case 2}

Figure 16 shows the LDR output as 0 on the LCD screen. This means light is present.

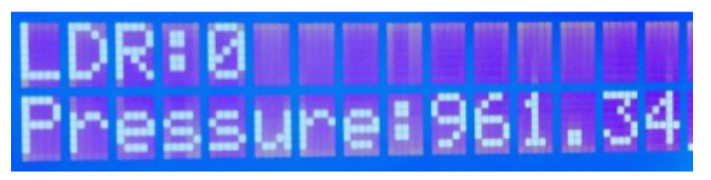

Figure 16 Output values of LDR and pressure on LCD for Case 2

\section{Gas and Sound sensor output on LCD:}

Figure 17 shows the sample LCD snapshot with gas and sound pollution values as 1 . Gas is 1 means that hazardous gases are absent, and sound pollution 1 means that sound pollution is negligible (within limits).

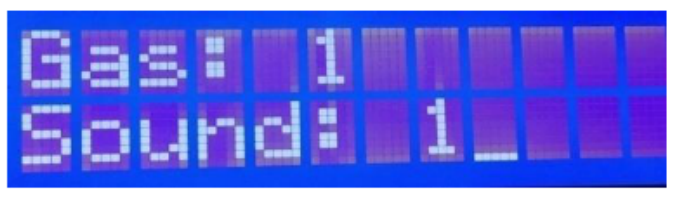

Figure 17 Output values of Gas and Sound on LCD 


\section{CONCLUSIONS}

In this paper, a prototype of Pollution and Climate monitoring system is implemented using the concept of Internet of Things. The various parameters of environment including temperature, humidity, atmospheric pressure, light intensity and presence of hazardous gases are measured, along with user location continuously at regular intervals. This system monitors above listed factors and provides dynamic data sheet on a Webpage which can be accessed from any part of the world. Such a data sheet is useful to monitor the atmospheric changes and take appropriate action with the parameters exceed certain threshold.

\section{REFERENCES}

[1] Somansh Kumar andAshish Jasuja, "Air quality monitoring system based on IoT using Raspberry Pi", International Conference on Computing, Communication and Automation (ICCCA), 5-6 May 2017, G.Noida, India, pp.1341-1346, IEEE.

[2] Harsh N. Shah, Zishan Khan, Abbas Ali Merchant, Moin Moghal, Aamir Shaikh, Priti Rane, "IOT Based Air Pollution Monitoring System", International Journal of Scientific \& Engineering Research, Vol. 9, Issue 2, Feb.2018, pp. 62-66.

[3] Gourab Sen Gupta andVu Minh Quan, "Multi-sensor integrated system for wireless monitoring of greenhouse environment", IEEE Sensors Applications Symposium (SAS), 12-14 March 2018, Seoul, South Korea, pp.1-6, IEEE.

[4] Nadjet Djebbri andMounira Rouainia, "Artificial neural networks based air pollution monitoring in industrial sites", International Conference on Engineering and Technology (ICET), 21-23 Aug. 2017, Antalya, Turkey, pp.1-5, IEEE.

[5] Mitesh Rathod,Ranjana Gite,Anushka Pawar,Shoomiren Singh,Pranav Kelkar, "An air pollutant vehicle tracker system using gas sensor and GPS", International conference of Electronics, Communication and Aerospace Technology (ICECA), 20-22 April 2017, pp. 494-498, Coimbatore, India, IEEE.

[6] https://www.raspberrypi.org/

[7] https://cdn-learn.adafruit.com/

[8] http://gas-sensor.ru/pdf/combustible-gas-sensor.pdf

[9] https://www.gps.gov/systems/gps/

[10] https://en.wikipedia.org/wiki/PuTTY.

[11] Richard L. Halterman, "Learning to Program with Python", 2011 (www.cs.uky.edu/).

[12] Larry Ullman, "PHP for the Web", Peachpit Press, San Francisco, 2016.

[13] Dr. N. Gomathi, P.B. Senthil Kumar, Haritha S, Sivaiah P, Sai Sowmiya G, Internet of Things Based Accident Detection and Prevention, International Journal of Mechanical Engineering and Technology 8(9), 2017, pp. 196- 204.

[14] M. Muhaidheen and Dr.S. Muralidharan, Internet of Things Based Advanced Security System for Atm, International Journal of Mechanical Engineering and Technology, 9(8), 2018, pp. 722-726.

[15] K.S. Parimala, Sirisha Yerraboina, N. Aruna Jyothi and Archana Dash, Monitoring the Water Storage Facilities using Internet of Things, International Journal of Civil Engineering and Technology, 9(6), 2018, pp. 1507-1516.

[16] Akanksha Bali, Mohita Raina and Simran Gupta, Study of Various Applications of Internet of Things (IOT). International Journal of Computer Engineering and Technology, 9(2), 2018, pp. 39-50.

[17] Salakapuri Rakesh and Prof. Nagaratna P Hegde, Internet of Things and Big Data Analytics for Developing Smart Cities: A Review. International Journal of Computer Engineering and Technology, 9(3), 2018, pp. 42-46. 